\title{
ABUSO E EXPLORAÇÃO SEXUAL DE CRIANÇAS E ADOLESCENTES: ESTRATÉGIAS DE PREVENÇÃO NA REDE DE PROTEÇÃO
}

\author{
Maria Nilvane Zanella* \\ Angela Mara de Barros Lara**
}

\begin{abstract}
RESUMO
O artigo possui como objetivo elaborar uma discussão teórico-metodológica sobre o tema abuso e exploração sexual de crianças e adolescentes. Para articular o objeto optou-se por elencar uma série de informações que contribuem para diferenciar o abuso e a exploração sexual, o comportamento dos abusadores e das vítimas, os mitos e a realidade em torno do tema, os sinais e sintomas e, finalmente, os traumas daqueles que sofrem abuso. A pesquisa de cunho bibliográfico aborda as informações divulgadas pelo Observatório Nacional dos Direitos da Criança e do Adolescente (OBS) com vistas a melhor compreender o perfil das crianças e adolescentes abusados em relação ao critério idade e sexo. Para finalizar, apresentamos informações práticas sobre como a escola pode operacionalizar a rede de proteção e a formação de profissionais que atuam na rede de atendimento básico da criança e do adolescente em municípios de médio e pequeno porte.
\end{abstract}

Palavras-chave: Crianças e adolescentes. Violência. Abuso sexual. Exploração sexual. Rede de proteção.

\begin{abstract}
ABUSE AND SEXUAL EXPLOITATION OF CHILDREN AND TEENS: PREVENTION STRATEGIES IN PROTECTION NETWORK

The paper aims to develop a theoretical and methodological discussion about the abuse and sexual exploitation of children and adolescents theme. To articulate the object it was decided to list a series of information that contribute to differentiate the abuse and sexual exploitation, the behavior of abusers and victims, the myths and reality surrounding of the theme, the signs and symptoms and, finally, the traumas of those who suffer abuse. The bibliographic nature of this research addresses the information disclosed by the National Observatory for the Rights of Children and Adolescents (OBS) in order to better understand the profile of children and adolescents abused in relation to age and gender criteria. Finally we present practical information on how the school can operate the safety net and the training of professionals working in primary
\end{abstract}

\footnotetext{
* Doutoranda em Educação pela Universidade Estadual de Maringá. (UEM). Mestre em Educação pela Universidade Estadual de Maringá (UEM). Mestre em Políticas e Práticas em Adolescente em Conflito com a Lei pela Universidade Bandeirante de São Paulo (UNIBAN/SP). Especialista em Gestão em Centros de Socioeducação. Pedagoga. E-mail: nilvane@gmail.com

** Pós-Doutora em Educação pela Universidade Federal de Santa Catarina (UFSC). Graduada em Pedagogia pela Universidade Estadual de Maringá (UEM). Professor Associado da Universidade Estadual de Maringá (UEM) e do Programa de Pós-Graduação em Educação: mestrado e doutorado. E-mail: angelalara@ymail.com
} 
care of the child network and adolescents in medium and small cities.

Keywords: Children and adolescents. Violence. Sexual abuse. Sexual exploitation. Protection net.

\section{RESUMEN}

\section{ABUSOS DESHONESTOS Y LA EXPLORACIÓN SEXUAL DE NIÑOS Y ADOLESCENTES: ESTRATEGIAS DE PREVENCIÓN EN LA RED DE PROTECCIÓN} El artigo posee como ojetivo elaborar una discusión téorico metodologica sobre el asunto abusos dehonestos y exploración sexual de niños y adolescentes. Para articular el objeto se optó por enumerar una serie de informaciones que atribuyen para distinguir el abuso y la exploración sexual, el comportamiento de los abusadores y de las víctimas, los mitos y la realidad alrededor del asunto, los sinales y síntomas y, por fin los traumas de aquelllos que sufren abusos. La encuesta de cuño bibliografico traee informaciones divulgadas por el Observatorio Nacional de los Derechos de los Niños y del Adolescente (OBS) con miras a mejor compreender el perfil de los niños y adolescentes abusadas en relación al criterio edad y sexo. Para finalizar presentamos informaciones práticas sobre como la escuela puede poner en práctica la red de protección y la formación de profisionales que actúan en la red de atención basico de los niños y del adolescente en municipio de mediano y pequeño magnitud.

Palabras claves: Niños y adolescentes. Violencia. Abusos deshonestos. Exploración sexual. Red de protección.

\section{Introdução}

O abuso sexual de crianças e adolescentes possui relação com o contexto histórico da sociedade, por isso não é possível estabelecer uma definição universal para o termo que possui significados diferentes, relacionados à cultura de uma determinada sociedade. Mundialmente, a definição do que significa ser criança em relação à faixa etária também não possui uma caracterização única.

A Convenção sobre os Direitos da Criança (CDC), aprovada em 1989, pela Organização das Nações Unidas (ONU), trata todos aqueles que possuem idade inferior a 18 anos de idade como criança. Devido a essa concepção jurídica, as legislações internacionais utilizam o termo menor ${ }^{1}$ sem restrições. A legislação brasileira, entretanto, promulgada sob o alicerce jurídico da Constituição da República Federativa do Brasil em 1988, optou por realizar uma separação etária entre crianças

1 As normativas internacionais que orientam as legislações nacionais de defesa dos direitos da criança e adolescentes utilizam o termo "menor" para tratar aqueles que possuem idade inferior a 18 anos. com idade até 11 anos e adolescentes com idade entre 12 e 18 anos incompletos. Essa alteração normativa e a negação dos termos utilizados nas legislações anteriores ao Estatuto da Criança e do Adolescente (1990) contribuíram para que o termo "menor" fosse negado formalmente e passasse a ser considerado pejorativo na área social, ainda que ele esteja engendrado nas relações sociais estabelecidas.

As variações de cada nação, no que se refere à idade e à não diferenciação entre crianças e adolescentes, contribui para que não exista uma definição global que estabeleça se uma pessoa menor de 18 anos está sendo abusada sexualmente. Em relação à exploração sexual, as legislações são mais rígidas, visto que alguns países consideram essa prática profissional um crime previsto em lei, tanto para quem se deixa explorar, quanto para o aliciador ou para o usuário do serviço.

Recentemente, na Espanha, "Um homem, natural do Equador, abusou sexualmente de uma criança 
do sexo feminino - 12 anos de idade - alegando que tal ato não é considerado crime no seu país" (ABUSO..., 2013). O caso ganhou repercussão mundial pelo fato de o acusado alegar que no Equador a mulher, desde o início da adolescência, estaria apta a manter relações sexuais, desde que fosse do seu consentimento. Tal assertiva, baseada no artigo 21 do Código Civil Equatoriano de 1861, considera criança a pessoa que ainda não completou sete anos de idade; pré-adolescente, o menino, entre sete e 14 anos incompletos e a menina que possui entre sete e 12 anos de idade. Ao completar 18 anos a pessoa torna-se adulta e todos aqueles que ainda não o completaram são considerados menores $^{2}$ (EQUADOR, 1861). Assim, pelo Código Civil a menina torna-se adolescente dois anos antes que o menino, e, nesse caso, a lei permite a relação sexual com pessoas maiores de idade, desde que o ato seja consensual.

No caso especificado, a justiça espanhola resolveu o impasse da seguinte forma: "[...] condenou [o acusado] a três anos de prisão e ao pagamento de uma indemnização de 3 mil euros" (ABUSO..., 2013). Ou seja, no julgamento considerou-se pertinente aplicar a Lei espanhola, local em que ocorreu o fato, e o jovem de nacionalidade equatoriana foi considerado um abusador sexual de uma menina de 12 anos.

O exemplo citado contribui para compreendermos que o abuso sexual de crianças e adolescentes é um fato datado historicamente, possui contextos culturais, étnicos e, também, de luta de classes, tendo em vista não apenas que os padrões de cuidado com as crianças mudaram ao longo da história da humanidade, mas também que a quantidade e a qualidade do cuidado e da proteção estão relacionadas com as condições financeiras da família, ainda que muitas vezes famílias com maiores condições financeiras cometam abusos e violência contra as crianças e os adolescentes.

Até o século IV era natural que as crianças que nascessem com alguma deficiência física ou motora fossem sacrificadas. Do século IV ao século XIII

\footnotetext{
2 Art. 21 - Llámase infante o niño el que no ha cumplido siete años; impúber, el varón, que no ha cumplido catorce años y la mujer que no ha cumplido doce; adulto, el que ha dejado de ser impúber; mayor de edad, o simplemente mayor, el que há cumplido dieciocho años; y menor de edad, o simplemente menor, el que no ha llegado a cumplirlos. (EQUADOR, 1861, tradução nossa).
}

as crianças passaram a ser mantidas distantes emocionalmente dos pais, sendo comum o abandono ou a sua venda para a escravidão. A partir do século XVI, por exemplo, muitas crianças do sexo masculino vieram para o Brasil nas grandes navegações como aprendizes de marinheiros ${ }^{3}$ ou para auxiliar os jesuítas na docilização dos tupinambás. ${ }^{4}$ As meninas, por sua vez, eram trazidas para cá a fim de desposarem os portugueses e contribuírem com a povoação da nova colônia. Somente no século XVIII, com a invenção da escrita e da educação escolar, houve a construção da infância como uma categoria e começou-se a pensar em uma nova forma de institucionalizá-la, ensinando às crianças bons hábitos, comportamentos adequados em público e boas maneiras. A partir do século XIV até o século XVII, os pais começaram a ter uma maior ligação emocional com as crianças, mas para moldá-las utilizavam a repressão e os castigos físicos. A influência de Rousseau ${ }^{5}$ contribuiu para que a criança se tornasse o centro do processo educativo e a educação passou a ser, ideologicamente, a resposta para todos os problemas sociais.

Na educação do século XIX, a ideologia moldou a dimensão pedagógica com o principal objetivo de manter a coesão social. A partir de então, tornou-se necessário fazer com que a criança correspondesse às expectativas dos outros e, por isso, tornou-se comum que o comportamento dos adultos enquanto pais representasse uma repetição da forma como foram tratados quando crianças, ou ainda, o seu contrário, a negação disso.

As tradições culturais são significativas nos cuidados que os pais têm com os filhos. Em algumas culturas as

[...] surras severas para garantir a obediência e a aceitação das normas culturais não são considera-

3 Os meninos interessavam aos marinheiros por consumirem menor quantidade de comida e por necessitarem de camas menores, sobrando maior espaço para as mercadorias.

4 Tupinambá é o nome de um povo indígena brasileiro composto de 100 mil habitantes e descendentes da tribo tupi que até o século XVI habitava algumas regiões do litoral brasileiro. Os tupinambás foram a nação indígena mais conhecida pelos navegadores europeus.

5 Jean-Jacques Rousseau (1712-1778) acreditava que a criança era importante em si mesma, e não como um meio para um fim. Além disso, valorizava a vida intelectual e emocional da criança, dizendo que a infância é o estágio da vida no qual o homem mais se aproxima do estado de natureza. As virtudes infantis como espontaneidade, pureza e alegria deveriam ser cultivadas e cultuadas (ROUSSEAU, 1995, 1999). 
das abusivas, mas são consideradas abusivas [...] algumas tradições ocidentais, tais como deixar os bebês sozinhos na própria cama ou no próprio quarto durante a noite, estabelecer horários de amamentação rígidos ou deixar que chorem sem atendê-los imediatamente. (SANDERSON, 2005, p. 3).

Essas diferenças significam, entretanto, a definição de um padrão de comportamento que é aceitável em uma determinada sociedade. Pensando em uma realidade local brasileira, o estabelecimento de relações sexuais entre um adulto e uma criança ou adolescente não é considerado legalmente aceito pelas normativas nacionais que o Brasil adotou a partir de 1990. Ocorre que, devido a uma questão cultural, ainda encontramos localidades em que a prática não causa incômodos na comunidade, sendo justificada pelos membros.

As formações sobre o tema com professores, conselheiros de direitos e conselheiros tutelares demonstram que existe uma incompreensão do que significa o abuso de crianças e uma naturalização da exploração sexual de adolescentes. Podemos dizer que, se em alguns casos os membros da comunidade não percebem o abuso sofrido pelas crianças, em outros fingem não ver ou naturalizam a exploração sexual, especialmente quando se trata de meninas pertencentes à classe mais desfavorecida dos meios de produção. Nesse sentido, considerando-se que muitas determinações relacionadas ao tema estão para além das nossas possibilidades de interferência, significando também uma mudança na ordem econômica vigente, o primeiro passo a ser dado é produzir conhecimento na área de formação dos profissionais que atuam com crianças e adolescentes.

O processo histórico de humanização do homem $^{6}$ sempre esteve relacionado com a transformação da natureza pelo trabalho. ${ }^{7}$ Assim, ao modificar a natureza o homem também se modificava e estabelecia relações com os seus iguais, ainda que no início desse processo histórico a

6 Neste artigo quando falamos de homem/homens estamos nos referindo aos homens e mulheres que pertencem ao gênero humano, constituído necessária e concretamente por homens e mulheres.

7 Pressupomos o trabalho como uma atividade exclusivamente humana, consciente e proposital que se diferencia das atividades instintivas e genéticas desenvolvida pelos animais. O ser humano, quando transforma a natureza por meio do trabalho, transforma-se a si próprio, ou seja, ele não é apenas um sujeito que trabalha, ele é, também, um produto desse trabalho (MARX, 1996). família não se orientasse pelo modelo que conhecemos atualmente (ENGELS, 2012).

No capitalismo, o trabalho não consegue realizar a função de humanização, ao contrário, o homem é compelido a competir e se superar, permanentemente. As suas conquistas, quando realizadas, ocorrem por meio do esforço individual e da negação de atividades de lazer, arte, descanso e da própria família. A realização dessas atividades demanda condições financeiras e tempo que o homem na busca pela sobrevivência não consegue dispor, ainda que todo o seu tempo seja dedicado a alcançar essas condições financeiras. Assim, o homem não apenas não consegue manter relações sociais para além do ambiente de trabalho, como ainda é compelido a se cobrar, permanentemente, por isso.

Essa cobrança leva os homens e as mulheres cada vez mais cedo a buscar alívio no uso e abuso das substâncias psicoativas (álcool e drogas), nos relacionamentos deturpados, nos vícios das jogatinas, enfim, em atividades que lhes proporcionem uma satisfação imediata e, ao menos momentaneamente, livre de cobranças. Essas atividades contribuem para o processo de desumanização do homem e para o aumento da violência em todas as suas formas. Assim, o sujeito desumanizado promove também a desumanização do outro, o que explica, por exemplo, o fato de abusadores sexuais de crianças negarem os danos causados às crianças abusadas, distorcendo as experiências das crianças como vítimas, desvalorizando suas fragilidades, as desumanizando. Por isso, quando discutimos abuso e exploração de crianças e adolescentes, falamos dos efeitos, e discutir a causa é sempre retornar aos princípios do liberalismo e tecer a crítica ao sistema capitalista, já evidenciada por Marx.

Quando marcamos nossa orientação teórico-metodológica na elaboração do texto, evidenciamos que estamos conscientes de que discutir temas relacionados à violência é sempre discutir o efeito e nunca as causas do processo que envolve a desumanização. Assim, ainda que as propostas aqui elencadas possuam limites, a nossa exposição busca contribuir para amenizar a violência provocada pelo abuso e a exploração sexual de crianças e adolescentes.

$\mathrm{O}$ artigo busca, em um primeiro momento, evidenciar a necessidade de uma desnaturalização do 
abuso e da exploração sexual de crianças e adolescentes, esclarecendo pontos que são tabus quando se trata do tema. Em seguida, apresentamos os dados coletados no site do Observatório Nacional dos Direitos da Criança e do Adolescente (OBS). A análise em âmbito estadual e nacional foi realizada a partir da seleção de dois critérios: a idade e o sexo. Finalizamos o artigo com sugestões de como operacionalizar a rede de proteção e a formação de profissionais que atuam na rede de atendimento básico da criança e do adolescente em municípios de pequeno porte.

\section{Conceitos e definições}

A violência tornou-se presente cotidianamente na vida das pessoas a partir da democratização dos meios de comunicação. Entretanto, a despeito de uma violência que passou a ser comum, existe ainda uma violência invisível para uma parte da sociedade: trata-se do abuso e da exploração sexual sofrido por crianças e adolescentes.

A definição de violência realizada pela Organização Mundial da Saúde (OMS) associa a intencionalidade do ato com o resultado produzido, tendo em vista que os incidentes não são intencionais e, por esse motivo, a violência é considerada:

O uso intencional da força física ou do poder, real ou em ameaça, contra si próprio, contra outra pessoa, ou contra um grupo ou uma comunidade, que resulte ou tenha grande possibilidade de resultar em lesão, morte, dano psicológico, deficiência de desenvolvimento ou privação. (ORGANIZAÇÃO MUNDIAL DA SAÚDE, 2002, p. 5).

Ao utilizar os termos poder e uso intencional da força física, a OMS incluiu no conceito "[...] a negligência e todos os tipos de abuso físico, sexual e psicológico, bem como o suicídio e outros atos de autoabuso" (ORGANIZAÇÃO MUNDIAL DA SAÚDE, 2002, p. 5). O abuso e a exploração sexual de crianças e adolescentes é classificada como uma violência interpessoal que pode ocorrer na família ou na comunidade. Os tipos de prevenção são caracterizados pela OMS em níveis primário (evitar a violência antes que ela ocorra), secundário (respostas imediatas como serviços de emergência, assistência pré-hospitalar etc.) e terciário (relacio- nados à assistência, reabilitação, integração e redução do trauma). Os três níveis possuem relações com o tempo (antes, imediatamente após ou em longo prazo). Os dois últimos níveis são também aplicados para perpetradores de violência e, geralmente, são determinados como parte da pena, no âmbito do judiciário.

O primeiro nível, quando atribuído a pessoas que cometeram violência, é agrupado em tipos de intervenções: universal, selecionada e indicada. A intervenção universal não considera os riscos individuais e visa atingir a população em geral; as intervenções selecionadas consideram um determinado grupo em maior situação de risco; e as intervenções indicadas são as abordagens voltadas àqueles que já demonstraram um comportamento violento. A OMS defende que exista um maior investimento nas ações primárias de prevenção, pois para ela a violência "[...] é um problema multifacetado, com raízes biológicas, psicológicas, sociais e ambientais" (ORGANIZAÇÃO MUNDIAL DA SAÚDE, 2002, p. 16).

Convém mencionar que a violência é também um problema econômico. Nessa perspectiva, a intervenção nas causas da violência pressupõe estabelecer uma rede de proteção local, de forma a viabilizar o contato entre os profissionais da educação, da saúde, da assistência etc., formando parcerias multissetoriais e a constituição de programas piloto e projetos de pesquisa em universidades que estudem o tema. A OMS define como abuso e maus-tratos contra crianças e adolescentes:

[...] todas as formas de tratamento doentio físico e/ou emocional, abuso sexual, negligência ou tratamento negligente, exploração comercial ou outro tipo de exploração, resultando em danos reais ou potenciais para a saúde, sobrevivência, desenvolvimento ou dignidade da criança no contexto de uma relação de responsabilidade, confiança ou poder. (ORGANIZAÇÃO MUNDIAL DA SAÚDE, 2002, p. 59).

A exploração sexual foi retratada no filme Anjos do Sol, de 2006, que apresentou de maneira inédita essa realidade no Brasil. O roteiro foi livremente inspirado em vários artigos publicados na imprensa brasileira sobre o tema e conta a história de Maria, uma menina vendida pelo pai e, posteriormente, leiloada como virgem para homens de grande 
poder aquisitivo. Os créditos finais do filme apresentam dados estimativos de que 100 mil crianças eram exploradas sexualmente no Brasil no ano da filmagem (ANJOS..., 2006). Sanderson (2005), entretanto, baseado em pesquisas de organismos multilaterais, aponta que no ano de 2000 havia no país uma taxa de prevalência de exploração sexual e comercial de 600 mil crianças, sendo importante lembrar que as políticas trazem um enfoque de campanhas de combate à prática em períodos de férias, turismo e festas. Nesses períodos, o país recebe grande número de visitantes que veem facilitada a prática do turismo sexual e o acesso às crianças e adolescentes oriundos de famílias mais empobrecidas. Convém mencionar que para um real e efetivo combate a essas práticas é necessário mais que campanhas esporádicas em períodos de Copa do Mundo e Olimpíadas.

Os agravos causados às crianças podem ser classificados em quatro tipos de maus-tratos: abuso físico, abuso sexual, abuso emocional e negligência. Os abusos físicos são os atos que causam real dano físico ou a possibilidade de um dano, como, por exemplo, bater, sacudir, arremessar, envenenar, queimar, afogar ou sufocar uma criança. Os maus-tratos emocionais também causam efeitos severos no desenvolvimento da criança, transmitindo a ela o sentimento de inutilidade e inadequação, expondo a criança ao ridículo, promovendo atos denegridores, ameaças, intimidações, discriminação e a rejeição. Esse tipo de abuso está presente em todos os tipos de maus-tratos, mas também pode ocorrer isoladamente (SANDERSON, 2005). A negligência significa que os responsáveis estão falhando, por condições que dependem exclusivamente da sua vontade e não por situações de pobreza ou de ausência de políticas públicas e sociais. Os pais ou cuidadores negligentes deixam, intencionalmente, de ofertar o acesso à saúde, educação, nutrição, abrigo, roupas, cuidados de higiene - expondo a criança às drogas e a ambientes inadequados -, bem como a condições adequadas para o desenvolvimento emocional e a segurança da criança. $\mathrm{O}$ abuso sexual remete ao ato de:

Forçar ou incitar uma criança ou um jovem a tomar parte em atividades sexuais, estejam ou não cientes do que está acontecendo. As atividades podem envolver contato físico, incluindo atos penetrantes (por exemplo estupro ou sodomia) e atos não-penetrantes. Pode incluir atividades sem contato, tais como levar a criança a olhar ou produzir material pornográfico ou a assistir a atividades sexuais ou encorajá-la a comportar-se de maneiras sexualmente inapropriadas. (SANDERSON, 2005, p. 5).

O abuso sexual resulta na gratificação sexual do violador e pode ocorrer com ou sem contato físico, abrangendo diversos graus de força física e psicológica como chantagem ou ameaça. $\mathrm{O}$ abuso sem contato inclui exposição indecente, exibicionismo, ${ }^{8}$ voyeurismo, ${ }^{9}$ exibir filmes pornográficos para crianças, fotografá-las para produzir material pornográfico, observá-las nuas ou utilizando o banheiro, bem como manifestar comportamento sexual na frente da criança etc. $\mathrm{O}$ abuso com contato ocorre quando a criança é beijada, penetrada ou tocada em suas partes íntimas de maneira inapropriada, quando ela é induzida a tocar a genitália de outra pessoa, a praticar ou receber sexo oral, inserir objetos em suas partes íntimas e, ainda, quando é induzida a praticar atividades sexuais, inclusive com animais.

Para completar a definição é importante mencionar que toda exploração sexual de crianças e adolescentes constitui um abuso, mas nem todo abuso significa que existiu uma exploração sexual. A exploração sexual de crianças corresponde à realização de favores sexuais em troca de um benefício financeiro para si própria ou para outros. Ou seja, é o ato de gratificar ou satisfazer as necessidades sexuais de outra pessoa, induzindo ou coagindo a criança para que esta se engaje em atividades sexuais pelas quais pode ser remunerada ou não, mas que produza lucro para um terceiro. A exploração sexual é considerada uma das piores formas de violação dos direitos da criança, sendo caracterizada como situação análoga ao trabalho escravo.

O abuso sexual em crianças é caracterizado como o envolvimento de crianças e adolescentes

\footnotetext{
8 A intenção do exibicionista é chocar a criança, visto que a experiência pode ser assustadora para ela. O exibicionismo também pode ser uma forma de naturalizar o abuso sexual, quando o abusador é alguém das relações intrafamiliares da criança. Da mesma maneira, é considerado abuso sexual mostrar para crianças fotos ou vídeos pornográficos, fotografar crianças nuas ou em posições sedutoras com objetivos sexuais.

9 O voyeur se satisfaz através da observação de atos ou órgãos sexuais de outras pessoas, de forma oculta. A experiência pode perturbar e assustar a criança ou adolescente. Hoje em dia, muitas dessas pessoas têm buscado fotos de crianças nuas na internet, o que também é considerado crime.
} 
em atividades sexuais com pessoas que possuem uma idade maior que a do abusado. Além da idade existe também diferença em relação ao tamanho e ao poder. A pessoa possui autoridade sobre a criança que é utilizada como

[...] objeto sexual para a gratificação das necessidades ou dos desejos, para a qual ela é incapaz de dar um consentimento consciente por causa do desequilíbrio no poder. Por isso, é considerado abuso sexual [...] quaisquer atos impostos à criança ou ao adolescente por qualquer pessoa dentro do âmbito da família, ou fora dela, que abuse de sua posição de poder e confiança. (SANDERSON, 2005, p. 17).

$\mathrm{O}$ abuso pode ser ocasionado por pessoas da família (pai, mãe, padrastos, madrastas, amigos da família que residam na mesma casa, tios, tias, irmãos, irmãs, irmãos adotivos, primos, avós e todos os membros da família ampliada) e fora da família (babás, funcionários de Centros de Educação Infantil, professores, responsáveis etc.) e membros da comunidade como vizinhos, comerciários, religiosos, amigos adolescentes e demais trabalhadores e moradores das redondezas que tenham autoridade e poder sobre a criança com alguma diferença de idade. Existem ainda os casos em que o abusador não pratica o ato, mas obriga duas crianças em idades iguais ou diferentes, com ou sem grau de parentesco, a praticar atos libidinosos para satisfazer a sua vontade.

\section{Crianças e adolescentes abusados: quem são as vítimas e os abusadores?}

Os dados colhidos no site do Observatório Nacional dos Direitos da Criança e do Adolescente (OBS) sobre as denúncias realizadas no Disque 100 demonstram a incidência de um maior número de abusos contra meninas do que contra meninos. ${ }^{10}$

10 O site do Observatório Nacional dos Direitos da Criança e do Adolescente era uma área técnica da Secretaria de Direitos Humanos da Presidência da República (SDH/PR) que desenvolvia ações de qualificação dos processos e instrumentos de gestão em direitos da criança e do adolescente. O site foi lançado em 18 de agosto de 2009, com o objetivo de integrar e compartilhar informações sobre implementação e acompanhamento das políticas públicas na garantia dos direitos da criança e do adolescente no país. O site perdeu sua funcionalidade com a promulgação da Medida Provisória $\mathrm{n}^{\circ} 726$, de 12 de maio de 2016, que revogou a organização dos Ministérios e da Presidência da República (BRASIL, 2016; FUNDO DAS NAÇÕES UNIDAS PARA A INFÂNCIA, 2009).
Não há dúvidas de que crianças de ambos os sexos são vítimas. Sanderson (2005) identificou em sua pesquisa que $73 \%$ eram do sexo feminino e $27 \%$ do sexo masculino. Pede-se cuidado na análise desses dados, pois o maior número de denúncias por mulheres pode estar relacionado com o estigma de culturas homofóbicas, deixando o abuso masculino mais obscuro do que o abuso feminino.

Em relação à idade, os dados nacionais demonstram que o maior número de denúncias é realizado por adolescentes, o que pode significar que estes, por possuírem uma maior autonomia, se sentem mais protegidos e seguros para denunciar e identificar quando são abusados. O abuso sexual em crianças pode começar em qualquer idade. Existem registros médicos que comprovam a existência de doenças sexualmente transmissíveis em bebês que possuem semanas de vida, ainda que Sanderson (2005, p. 18) aponte que "[...] acredita-se que a faixa etária de maior risco seja aquela entre 5 e 12 anos, porém crianças cada vez mais novas estão sendo usadas na produção de imagens de pornografia infantil".

As crianças mais novas podem ter uma dificuldade maior em telefonar e identificar o abuso e o abusador, tendo em vista que o abusador lhe dirá que a relação é normal e faz parte de um relacionamento especial entre ambos. Outras crianças podem sentir medo das consequências da denúncia, visto que o abusador irá ameaçá-las. A pesquisa de Sanderson (2005, p. 18) constatou que "A maioria dos crimes é cometida por pessoas conhecidas da criança (87\%), muitas das quais nunca são denunciadas". Por isso, estão equivocados os pais, professores e profissionais que se preocupam em avisar as crianças apenas sobre o contato com pessoas estranhas, conforme a autora alerta: "A ideia de que predadores do sexo infantil são estranhos não mais reflete a realidade do abuso sexual em crianças e, na verdade, é um mito" (SANDERSON, 2005, p. 19). Ou seja, os pedófilos são pessoas comuns da comunidade e quase sempre são membros respeitados nela, sendo pessoas muito simpáticas que, em sua maioria (90\%), não são identificadas. A autora salienta que os primeiros estudos apontavam que mais de $90 \%$ dos abusadores eram homens. Entretanto, estudos mais recentes "[...] descobriram que entre $20 \%$ e $25 \%$ dos abusadores sexuais de crian- 
ças eram mulheres" (SANDERSON, 2005, p. 20). Há também evidências de que houve um aumento no número de abusos praticados por adolescentes (irmãos mais velhos, adotivos, primos, colegas, vizinhos etc.).

Sanderson (2005) explica que a sociedade tem dificuldade em aceitar que mulheres possam ser agressoras sexuais e consideram difícil entender como elas poderiam abusar sexualmente das crianças e adolescentes.

Pesquisas mostram que mulheres abusadoras de crianças cometem vários tipos de atos sexuais, que incluem tocar os genitais, forçar a criança a sugar-lhes os seios ou a genitália, masturbação mútua forçada, penetração da vagina ou do ânus da criança com objetos e o coito propriamente dito (SANDERSON, 2005).

Em algumas situações, essas mulheres promovem, também, o espancamento das crianças. A dificuldade de aceitação do abuso cometido por mulheres promove a descrença no relato da criança e do adolescente. As mulheres costumam escolher o horário de higiene íntima da criança para promover o abuso, dando a entender que a ação não é intencional. Nos casos em que mulheres adultas se relacionam com adolescentes do sexo masculino, o fato é visto com admiração e exaltação da masculinidade do jovem. Nesses casos, o menino é impedido moralmente de relatar ou reclamar do abuso, pois isso colocaria em xeque a sua própria sexualidade.

Geralmente, os abusadores estão inseridos na comunidade e possuem habilidades para identificar as crianças mais vulneráveis ao abuso. São homens e mulheres que se identificam mais com as crianças do que com os adultos e possuem um interesse excessivo nelas, embora isso não seja evidente antes dos abusadores ganharem a confiança dos pais e responsáveis. É possível que seus locais de trabalho deem a eles possibilidade para esse contato, sendo comumente gentis e com enorme capacidade de atrair crianças e seduzir os pais. Quando o interesse do abusador é o adolescente ou pré-adolescente, ele ganha a confiança deles, deixando-os fazer coisas que os adultos responsáveis não deixariam: ingerir bebidas alcoólicas, dirigir sem carteira, usar drogas, fumar e ter acesso a materiais pornográficos, inclusive para relativizar o abuso sexual.
Obviamente que não podemos nos esquecer do perigo das pessoas desconhecidas, que sequestram e até mesmo matam crianças e adolescentes. Entretanto, as pesquisas apontam que esse número é relativamente ínfimo, relacionado com os abusos cometidos por pessoas das relações pessoais da família, que antes de aliciar a criança promovem o aliciamento dos pais ou responsáveis.

O aliciamento é a forma que o abusador utiliza para preparar a criança e a sua família para o abuso sexual. As pesquisas de Sanderson (2005) identificaram que um abusador pode levar até 18 meses preparando o abuso sexual sem ser detectado. Com isso, podemos concluir que, inicialmente, o abusador conquista a família da criança e do adolescente para que possa ficar sozinho com a vítima sem causar desconfianças.

Não podemos deixar de mencionar que na contemporaneidade o aliciamento tornou-se mais simples pelo acesso facilitado de crianças e adolescentes à internet. Essa situação foi relatada em 2010 no filme Confiar, por exemplo. Na história, a adolescente Annie estabelece contato com um homem que finge se passar por um jovem de 16 anos pela internet. Após ser abusada sexualmente, tanto Annie quanto sua família demonstram dificuldade de compreender o que levou a menina a ser alvo de um predador (CONFIAR, 2010).

$\mathrm{O}$ uso livre e indiscriminado da internet em telefones celulares e redes sociais também têm contribuído para que crianças e adolescentes se coloquem em risco quando promovem a banalização tanto da exposição individual de imagens corporais quanto de práticas sexuais em dupla ou em grupos. Em um período de culto à imagem e às celebridades, crianças e adolescentes têm se permitido praticar o sexting ou o revenge porn. $\mathrm{O}$ sexting é definido, literalmente, como o envio de materiais pornográficos através de aparelhos celulares, e o revenge porn é a publicação de materiais pornográficos na internet sem o consentimento da (s) personagem (s) do vídeo, como forma de vingança. Essas imagens, ao caírem na rede, passam a alardear a intimidade dos jovens e a fomentar as inúmeras páginas manipuladas por pedófilos.

Os adolescentes, por sua vez, também costumam cometer abusos sexuais nas instituições escolares ou esportivas, se aproximando das crianças 
em atividades lúdicas ou nos banheiros da escola. As pesquisas de Sanderson (2005, p. 90) apontaram que "[...] quanto mais cedo as crianças forem identificadas e for-lhes proporcionado tratamento terapêutico, mais chances haverá de que elas não venham a praticar violências". Sabe-se que, quando descobertos casos de adolescentes abusadores, tanto os profissionais que atuam nas escolas, quanto os pais destes adolescentes costumam minimizar o fato, com vistas a evitarem escândalos. Entretanto, "O tratamento e a intervenção precoces podem muito bem desviá-lo de um padrão de violência sexual contra crianças por toda a vida" (SANDERSON, 2005, p. 96).

Levando-se em conta as evidências atuais, que mostram que uma em cada oito crianças sexualmente abusadas acaba abusando de outras crianças quando se torna mais velha ou quando fica adulta, parece imperativo que essas crianças obtenham ajuda apropriada para evitar esse círculo.

A natureza piramidal [do abuso e exploração sexual] indica que muitos pedófilos abusam de mais de 200 crianças antes de serem pegos [...]. Fato que leva ao seguinte raciocínio: cada pedófilo poderia potencialmente criar 25 futuros pedófilos e cada um deles poderia abusar de até 200 crianças. (SANDERSON, 2005, p. 229).

Os indicadores do OBS sobre as denúncias relativas ao abuso sexual de crianças e adolescentes identificam, nos diferentes estados, as mesmas similaridades com os dados nacionais, ou seja, as denúncias são em maioria referentes a adolescentes, e quando a comparação é o sexo, os números apontam que a maioria das denúncias refere-se ao abuso de meninas. Importante salientar que é preciso analisar com cuidado essas informações, visto que elas não refletem a realidade. Muitas vezes as denúncias não são realizadas e o aumento delas varia em acordo com as campanhas sobre o tema. Por isso, estados com campanhas incipientes podem ter um número inferior de denúncias, ainda que tenham um número maior de casos de abusos.

\section{As ações de proteção na comunidade}

Agora que já discutimos os conceitos e falamos sobre o que é, como ocorre e quem são os possíveis abusadores sexuais de crianças e adolescentes, precisamos abordar as ações de proteção primária para evitarmos que, na medida do possível, o abuso não aconteça e que, nos casos em que ele já tenha ocorrido, a vítima possa ser libertada dele o mais breve possível. Nessa perspectiva, temos que pensar em ações imediatas, de médio e longo prazo. Para tanto, precisamos evidenciar como os profissionais podem identificar as crianças que sofrem violência.

A criança ou o adolescente que possui uma autoestima diminuída, timidez, medo exagerado e pouca iniciativa pode tornar-se alvo de abuso sexual. Quando bebês, essas crianças possuem dificuldade em ganhar peso, apresentam um baixo desenvolvimento psicomotor para a idade e quando estão em idade escolar apresentam dificuldades de aprendizagem, agressividade exagerada, com dificuldade de reconhecer limites e, principalmente, sinais de um desenvolvimento sexual precoce para a idade, inclusive com comportamento sexual inadequado com amigos.

As famílias também podem dar sinais, por exemplo: famílias que possuem restrição para o contato e a ajuda dos profissionais; com pouco ou nenhum vínculo afetivo; que possuem critérios morais, religiosos e educacionais rígidos; que são coniventes ou impotentes frente ao comportamento violento de outras pessoas contra a criança; que apresentam desinteresse sobre a saúde e o desenvolvimento da criança; e que possuem históricos de violência contra idosos e mulheres.

Em relação aos adultos que praticam esse tipo de violência existem alguns sinais de alerta para identificá-los: adultos oriundos de famílias com histórico de violência e que foram maltratados na infância; adultos imaturos e com baixo limiar de frustração; adultos autoritários, pouco tolerantes, pouco flexíveis e que justificam o comportamento agressivo pelo trabalho, álcool, drogas, desemprego etc. Essas desculpas contribuem para que as mulheres não realizem a denúncia e a família se torne incapacitada de reagir contra a violência.

Os profissionais que atuam na rede de proteção básica precisam conhecer o que é o abuso sexual e como devem agir quando desconfiam que uma criança esteja sofrendo esse tipo de violência. Médicos, enfermeiros, dentistas, professores de todos os níveis e modalidades de ensino, assistentes 
sociais, psicólogos, conselheiros tutelares, agentes comunitários de saúde, cuidadores de Centros de Educação Infantil e educadores sociais que atuam em instituições de acolhimento e programas sociais, profissionais que atuam nos núcleos regionais de Ensino, estudantes universitários, coordenadores de estágio, enfim, todos os profissionais que atuam com crianças ou que formam profissionais que atuarão com elas precisam compreender o que é o abuso sexual, como ocorre e quem são os abusadores sexuais de crianças e adolescentes.

Ao desconfiar de alguma situação, o profissional deve conversar com a criança afastada dos pais. Geralmente, se sentindo segura ela contará o que aconteceu. Entretanto, o silêncio também pode significar uma defesa emocional frente às ameaças do abusador. São situações que devem ser denunciadas, ainda que signifique abuso físico e não necessariamente sexual: lesões incompatíveis com a idade da criança, como, por exemplo, bebês que ainda não possuem capacidade de engatinhar, rolar ou se arrastar; lesões em locais que são diferentes do relato do acidente; lesões em várias partes do corpo, especialmente, em áreas protegidas por roupas; lesões com diferentes estágios de cicatrização; repetições em internamentos e traumas e o retardamento na busca do atendimento médico. São evidências de que o corpo sofreu violência: arranhões, cortes, equimoses, queimaduras, mordidas, manchas que indiquem sucção (também chamada de chupão).

Por um lado, a maior dificuldade encontrada para se abordar esse tema com os profissionais que atuam na educação escolar é, por exemplo, convencê-los de que o abuso ocorre e não é algo tão incomum quanto possa parecer. Existe uma forte tendência em não se acreditar que alguém possa fazer algo nefasto para uma criança. Talvez pelo fato de que a própria pessoa seja incapaz de cometê-lo, ela também passa a acreditar que os demais membros da comunidade não o farão.

Não podemos esquecer que, culturalmente falando, a sociedade desconfia que os abusadores sejam os mendigos, doentes mentais, pessoas com características físicas ou mentais e, por isso, essas pessoas teriam maior dificuldade em se aproximarem das crianças. O seu contrário é verdadeiro. A tendência do abusador é ser uma pessoa gentil, educada, afável, conquistadora e pacienciosa.
Geralmente, quando as crianças contam para os professores situações que podem indicar um abuso, a tendência é que os profissionais acreditem que precisam de provas para fazer uma denúncia. Em algumas situações a escola chama os responsáveis, que como vimos é o próprio abusador, e relatam o que a criança contou. Após o fato, não é incomum a criança ser transferida de escola e os pais se mudarem de bairro e até mesmo de município. Em outras situações, os profissionais iniciam uma investigação paralela, conversando com parentes, contatando a instituição anterior que a criança estudava, interrogando um colega, irmão ou primo da criança. Ou seja, o assunto que deveria imediatamente ter sido denunciado ao Conselho Tutelar se torna motivo de fofoca institucional.

Não é incomum professores, estudantes universitários e cuidadores relatarem que não sabem o que fazer quando identificam que uma criança ou adolescente foi abusada ou está sendo assediada. Nos espaços de formação sempre evidenciamos que as denúncias devem ser feitas imediatamente. O próprio Estatuto da Criança e do Adolescente estabelece em seu artigo 13 que "Os casos de suspeita ou confirmação de maus-tratos contra criança ou adolescente serão obrigatoriamente comunicados ao Conselho Tutelar da respectiva localidade, sem prejuízo de outras providências legais" e evidencia no artigo 245 que é punível na forma da lei os profissionais que deixarem "[...] de comunicar à autoridade competente os casos de que tenha conhecimento, envolvendo suspeita ou confirmação de maus-tratos contra criança ou adolescente" (BRASIL, 1990, s/p). Ou seja, a denúncia deve ser realizada, ainda que exista apenas uma suspeita, e não cabe aos profissionais que atuam nas áreas de saúde, educação, assistência social etc. comprovarem o ato.

Às vezes a criança é encaminhada para um atendimento médico devido a manifestações físicas ou comportamentais que apenas aparentemente não possuem relação com abusos. Entretanto,

É comum crianças que foram vítimas de abusos sexuais apresentarem sintomas de infecção, lesões genitais, dores abdominais, constipação, infecções crônicas ou recorrentes do trato urinário ou problemas comportamentais. Ser capaz de detectar o abuso sexual infantil requer muita habilidade e familiari- 
dade com indicadores verbais, comportamentais e físicos de abuso. Muitas crianças revelarão o abuso para as pessoas que cuidam delas ou outros espontaneamente, embora também possa haver sinais físicos ou comportamentais indiretos. (ORGANIZAÇÃO MUNDIAL DA SAÚDE, 2002, p. 61).

É óbvio que existem cuidados que os profissionais que atuam diretamente com as crianças devem ter, evitando se colocar em risco e, principalmente, proteger a própria criança. Por isso, o correto é que a denúncia seja realizada pelo diretor ou coordenador da instituição. Os casos em que é necessário um maior cuidado, como, por exemplo, quando o abusador é um membro da instituição, o profissional pode utilizar, anonimamente, o serviço do Disque 100.

Nos municípios de pequeno porte o medo de efetuar a denúncia advém do fato de os membros da comunidade se conhecerem. Esse medo é fundamentado, especialmente, quando o possível abusador é uma pessoa influente e com uma melhor condição econômica. Nesses municípios não é incomum que os membros das instituições possuam, inclusive, laços de consanguinidade, sendo, por isso, aparentados, o que pode acarretar em constrangimento.

O desconhecimento e a inabilidade em atuar com situações de violência não estão restritos às instituições, mas também podem atingir os conselheiros tutelares. Em um caso específico, tomamos conhecimento de que o conselheiro tutelar relatou ao abusador de onde havia partido a denúncia relativa ao abuso. $O$ fato motivou que a criança fosse retirada do programa que a atendia. Importante salientar que o Conselho Tutelar possui o dever de manter o sigilo sobre a instituição e o nome da pessoa que efetivou a denúncia. Ainda que após o atendimento da vítima - físico e psicológico - a denúncia seja encaminhada pelo Conselho Tutelar ao Ministério Público, o sigilo será mantido.

O estado do Rio Grande do Sul inovou ao adotar a prática do depoimento sem dano para realizar as audiências de acusação contra pessoas que praticam abuso sexual. Nesse modelo, a criança é ouvida, separadamente, com a interpretação dos questionamentos feitos a ela por uma psicóloga da Vara da Infância e Juventude, o que torna o procedimento menos agressivo para a criança e mais humanizado.
Essa prática, entretanto, não é comum em todas as comarcas e estados do Brasil.

A discussão realizada sobre os procedimentos das instituições e profissionais que atuam com crianças e adolescentes quando identificam o abuso sexual contribui para que possamos compreender que a formação desses profissionais sobre o tema é primordial no combate ao abuso e à exploração sexual. Os profissionais que conhecem esse tema nas instituições podem promover atividades de autocuidado, ensinando às crianças como se proteger e denunciar alguém que as toque indevidamente. Ainda que não seja papel da escola dar esse tipo formação, ela pode promover atividades esporádicas e reuniões com pais para abordar o tema. De qualquer forma, um melhor conhecimento sobre o assunto pode contribuir para aumentar o número de denúncias.

O mesmo pode ocorrer nas universidades, quando prepara os universitários para realizar suas atividades de estágio. É bastante comum os estagiários identificarem situações de abuso físico e psicológico praticado nas instituições. Ocorre que, geralmente, nada é feito com isso, a não ser transformar os fatos em relatos que demonizam a instituição onde o abuso aconteceu. Cabe ao coordenador de estágio preparar os alunos para as situações que estes poderão vivenciar nessas instituições e estabelecer com eles passos a serem dados nos casos em que as situações forem identificadas.

Não é adequado que os estagiários conversem com a direção da instituição. Da mesma forma que o professor deve buscar o seu superior para efetivar a denúncia no Conselho Tutelar, o universitário deve buscar a coordenação de estágio e o coordenador de curso. Quando o caso não for grave, mas constituir algum tipo de violência simbólica, a universidade deve procurar a direção escolar e relatar o fato de maneira sigilosa e ética, evitando-se que a escola não ofereça mais o espaço para a realização dos estágios. Entretanto, quando o caso for grave como, por exemplo, situações de abuso sexual, imediatamente o Conselho Tutelar deve ser notificado.

Obviamente, os profissionais que atuam nas instituições sociais (psicólogos, assistentes sociais, terapeutas ocupacionais, educadores sociais etc.) possuem uma melhor formação e conhecimento 
sobre o tema, seja pelas ações realizadas anualmente em maio, seja pela própria formação acadêmica. Entretanto, em muitas situações os profissionais que participaram da formação no ano anterior não participam em anos subsequentes. Também ocorre que as palestras, por serem superficiais, acabam não dando uma formação sobre o assunto, mas apenas levantando algumas perspectivas de análise que não são mais retomadas no decorrer do ano. Por isso, a formação permanente sobre esses temas colaboram para combater a violência contra crianças e adolescentes, que quando não é combatida pode contribuir para que crianças e adolescentes se tornem, eles mesmos, violadores de direitos.

Outras ações podem ser realizadas pelas instituições que fazem parte da rede de proteção para minimizar as situações de violência. Reuniões de estudo de caso com membros da escola, do Conselho Tutelar, agentes comunitários de saúde, profissionais que atuam na assistência social, entre outros. As reuniões podem discutir casos em que a criança apresenta indícios de que algo não está em acordo com um desenvolvimento adequado. Nos encontros, os profissionais levam as informações que possuem sobre a família, a criança, a comunidade etc. para posteriormente darem encaminhamentos para a resolução ou acompanhamento do caso. Importante destacar que essa reunião envolve os profissionais que estão diretamente ligados à criança ou à família.

As reuniões da rede de proteção que discute a política e o combate à violência de uma forma mais generalizada no município fazem parte das ações de médio prazo e devem ser viabilizadas com a participação de representantes dos órgãos estaduais e municipais. No que tange as ações de médio e longo prazo, o planejamento deve ser realizado pelo Conselho Municipal dos Direitos da Criança e do Adolescente (CMDCA), que é a instância articuladora dos membros da comunidade e do orçamento disponível para as formações e as ações que serão viabilizadas.

Finalmente, é importante mencionar que a elaboração de um protocolo da rede de atenção e apoio municipal sobre o assunto significa articular a rede, dar formação aos membros da comunidade e estabelecer o fluxo de entrada das denúncias, dos encaminhamentos para os serviços e o que deve fazer cada um dos equipamentos disponíveis na rede municipal, que foram previamente diagnosticados antes do início da elaboração do protocolo.

\section{Considerações finais}

No decorrer do artigo buscamos elucidar o que é o abuso sexual e a diferença entre abuso e exploração sexual de crianças e adolescentes. Procuramos demonstrar que o indivíduo que abusa sexualmente de crianças e adolescentes não possui características físicas que o identificam, conforme demonstram os filmes e permanece no imaginário de pais, mães e profissionais que atuam com crianças. Assim, evidenciamos que o abusador pode ser homem, mulher ou adolescente que em sua maioria são conhecidos e frequentam a casa da criança. Esse abusador inicia o aliciamento tornando-se íntimo e confiável para a criança e para os responsáveis. O aliciamento possibilita que o abuso sexual ocorra de forma segura e o torne livre de suspeitas.

Crianças que sofreram abuso sexual, muitas vezes, só vão se dar conta da violência pela qual passaram após adultas, ou depois, decorrido um tempo do fato acontecido. $\mathrm{O}$ abusador insiste em dizer para a criança que ela desejava ser abusada, queria o ato, que ele e a criança possuem uma amizade especial e que ela o incentivou a fazê-lo. A criança acredita nisto porque em algumas situações sente prazer no desenvolvimento da sua sexualidade.

A força e o poder exercido pelo abusador em relação à criança impede que ela denuncie o fato por medo de uma possível violência contra alguém que ama (pais, irmãos etc.), contra si mesma e/ou ainda por medo de perder a relação especial constituída com o abusador. $\mathrm{O}$ abusador possui habilidades para reconhecer as crianças que são mais frágeis emocionalmente e, por isso, suscetíveis a manterem a relação em sigilo.

Os profissionais que atuam com crianças e adolescentes precisam identificar as características daquela que sofre abuso, para denunciarem o fato. Nessa perspectiva, o CMDCA é o órgão responsável por articular os espaços de formação desses profissionais, a rede de proteção para viabilizar os estudos dos casos, os encaminhamentos e uma instância macromunicipal que atuará na elaboração do Protocolo da rede de proteção e combate à violência da criança e do adolescente. 


\section{REFERÊNCIAS}

ABUSO sexual de menores: "Pensava que não era crime". Correio da Manhã, Lisboa, 16 jan. 2013. Disponível em: $<$ http://www.cmjornal.xl.pt/detalhe/noticias/internacional/mundo/abuso-sexual-de-menores-pensava-que-nao-era-crime>. Acesso em: 28 abr. 2013.

ANJOS do sol. Direção: Rudi Lagemann. Rio de Janeiro: Globo Filmes, 2006. 1 DVD (90 min).

BRASIL. Presidência da República. Medida Provisória no 726, de 12 de maio de 2016. Altera e revoga dispositivos da Lei no 10.683, de 28 de maio de 2003, que dispõe sobre a organização da Presidência da República e dos Ministérios. Brasília, DF, 2016. Disponível em: <http://www.planalto.gov.br/ccivil_03/_Ato2015-2018/2016/Mpv/ mpv726.htm>. Acesso em: 25 jul. 2016.

CONFIAR. Direção: David Schwimmer. Rio de Janeiro: Imagem Filmes, 2010. 1 DVD (104 min).

ENGELS, Friedrich. A origem da família, da propriedade privada e do Estado. Trad. Leandro Konder. 3. ed. São Paulo: Expressão Popular, 2012.

EQUADOR. Código Civil Equatoriano. Quito, 1861. Disponível em: <http://www.ecuamundo1.com/lex-dura-lex/c\%C3\%B3digo-civil-ecuatoriano/>. Acesso em: 28 abr. 2013.

FUNDO DAS NAÇÕES UNIDAS PARA A INFÂNCIA (UNICEF). Lançado o Portal do Observatório Nacional dos Direitos da Criança e do Adolescente. Brasília, 2009. Disponível em: < http://www.unicef.org/brazil/pt/ media_15670.htm>. Acesso em: 25 jul. 2016.

MARX, Karl. O Capital: crítica da economia política. Livro primeiro: o processo de produção do capital, Tomo 1. Prefácios e Cap. I a XII. São Paulo: Nova Cultural, 1996. (Os Economistas).

ORGANIZAÇÃO MUNDIAL DA SAÚDE (OMS). Relatório mundial sobre violência e saúde. Genebra, 2002. ROUSSEAU, Jean-Jacques. Emílio, ou da educação. Trad. Roberto Leal Ferreira. São Paulo: Martins Fontes, 1995.

Rousseau. São Paulo: Nova Cultural, 1999. (Os Pensadores).

SANDERSON, Christiane. Abuso sexual em crianças: fortalecendo pais e professores para proteger crianças de abusos sexuais. São Paulo: M. Books do Brasil, 2005.

Recebido em: 30.03 .2016

Aprovado em: 21.07.2016 